\title{
Six Minute Walk Distance and Reference Equations in Normal Healthy Subjects of Nepal Shrestha SK, Srivastava B
}

National Academy of Medical Sciences

Bir Hospital, Kathmandu, Nepal

\section{Corresponding Author}

Sanjeet Krishna Shrestha

National Academy of Medical Sciences (NAMS)

Bir Hospital, Kathmandu, Nepal

E-mail: Shrestha.sanjeet@gmail.com

\section{Citation}

Shrestha SK, Shristava B. Six Minute Walk Distance and Reference Equations in Normal Healthy Subjects of Nepal. Kathmandu Univ Med J 2015;50(2):97-101.

\begin{abstract}
Background

The self-paced six minute walk test is a simple assessment for sub-maximal functional capacity. It correlates well with sophisticated tests and gives good prediction for morbidity, mortality, quality of life and pulmonary functions.
\end{abstract}

\section{Objective}

To evaluate six minute walk distance in healthy adults to identify reference values and formulate reference equations.

\section{Method}

We conducted six minute walk test on 250 random volunteers at and above 18 years of age as per standard protocol. Age, gender, height and weight were measured. Pretest and post-test vital parameters were recorded including pulse oximetry. The six minute walking distance was identified in all subjects. Multiple regression analysis was done to formulate regression equations to predict six minute walking distance. This also correlated age, gender, height, weight, body mass index with six minute walking distance.

\section{Result}

The mean six minute walking distance was $489 \pm 86$ meters with males walking $509 \pm 82$ meters and females $445 \pm 78$ meters. Age, gender, weight and body mass index had significant contribution for prediction of six minute walking distance. Gender was the single most important predictor. Height had the least significance. Depending on coefficients of these variables we formulated three regression equations and tested them for accurate prediction. The two best equations were identified as: Predicted SMWD = 395-1.5xAge+2.47xWT-35.89xGender and Predicted SMWD = 440-1.82xAge-53.07xGender+5.12xBMI.

\section{Conclusion}

Gender, age and height are the most important predictors of six minute walking distance. Reference values and equations for both genders, different age groups with varying weights were derived for local population.

\section{KEY WORDS}

Predicted equation, reference values, six minute walk test. 


\section{INTRODUCTION}

Walking, a simple assessment of health, was standardized into a 12 minute test in $1968 .{ }^{1}$ The subjective recalling like: number of blocks walked, are less reliable than the objective measurements. ${ }^{2}$ Available objective methods range from simple stair climbing to cardiopulmonary exercise test (CPET). ${ }^{3,4}$ The self-paced six minute walk test (SMWT) does not require equipment and training. It assesses submaximal functional capacity by measuring six minute walk distance (SMWD). It evaluates the co-ordination of all the body systems during exercise. ${ }^{5}$ Popularly used in pulmonary rehabilitation SMWT has a good correlation with CPET., Studies show SMWD as a good predictor of morbidity, mortality and quality of life. ${ }^{8-11}$ Changes in SMWD after therapeutic interventions correlate better with subjective improvement in breathlessness. ${ }^{12,13}$ SMWD is also better reproduced than forced expiratory volume in first second (FEV1) in obstructive lung disease. ${ }^{13-16}$

The reference values and equations available for the SMWT for several countries help predict SMWD..$^{8-10}$ Percent predict of observed value to the calculated value provides a basis of comparison with healthy population. Despite the popularity there is limited data relating SMWD and reference values in south-east Asia.

SMWT is a cost-efficient modality for Nepal. As it is not technically demanding, its use can be widened to the primary health level. Until now, values and reference equations are only available for international communities. This study evaluates a local cohort for identifying reference range and equation in order to have comparative data for adults in Nepal.

\section{METHODS}

This was a prospective randomised study conducted on healthy adult volunteers at Shree Birendra Hospital, Chhauni and National Academy of Medical Sciences (NAMS), Bir Hospital, Kathmandu from July 2013 to June 2014. Ethical clearance was obtained from Institutional Review Board of NAMS. Total of 250 non-smoking healthy and willing volunteer's 18 years and above were included after informed written consent. Subjects with unstable angina, myocardial infarction, hypertension (>180/100 $\mathrm{mmHg}$ ), neurological, vascular and musculoskeletal abnormalities preventing walking, acute or chronic respiratory diseases and any recent thoracic and abdominal surgery were excluded from the study. Regular competing athletes were also excluded to avoid practice bias and outlier data.

All the tests were conducted as per 2002 American Thoracic Society (ATS) guidelines on SMWT. ${ }^{5}$ The SMWT was performed indoors, along a 30 meter long, flat and straight corridor with a hard surface in respiratory outpatient department. The start and turn-around points were marked on the floor using brightly coloured tapes.
The participants were asked to come in comfortable clothing and appropriate shoes for walking purpose. A light meal was allowed before morning or early afternoon tests. The subjects were asked to avoid vigorous exercise two hours before the test. After proper explanation and demonstration by research team, participants were asked to walk at own pace for six minutes after resting period of 10 minutes. No warm up periods were allowed. The initial part of ATS-SMWT worksheet was completed before SMWT. This included: Pre-walk Modified Borg Scale for Dyspnoea (MBSD), heart rate (HR), blood pressure (BP), and oxygen saturation $\left(\mathrm{SpO}_{2}\right) .{ }^{5} \mathrm{SMWD}$, Post-walk Vitals, $\mathrm{SpO}_{2}$ and MBSD were recorded in all subjects after the completion. None of the participants required termination of test or rest during the test due to normal health status. Volunteers who desaturated during the test below $90 \%$ were excluded at the time of re coding the worksheet.

The main objective of our study was to identify the reference range of SMWD in study population and formulate regression equation for its calculation. During the test we recorded age, gender, height (HT) and weight (WT) as independent variables as a possible determinants of SMWD. Later we calculated body mass index (BMI) as a possible alternative variable for HT and WT.

With power of multiple regression set at 0.8 , significance level alpha of 0.05 , minimum $\mathrm{R}^{2}$ targeted at $5 \%$ and total five independent variables we calculated the sample size of 250. The subjects were evaluated using IBM SPSS version 20. Descriptive statistics were used to express and evaluate demographic and vital parameters of the study populations. All categorical data were expressed as percents and ratios. All the numerical data were expressed as mean \pm standard deviation (SD). All five independent variables were checked for correlation with SMWD using Pearson Correlation. Assumptions for multiple regression analysis were tested before the actual analysis. After running multiple linear regression analysis, $\mathrm{R}$ (multiple correlation coefficient), $R^{2}$ (coefficient of determination) and adjusted $R^{2}$ were calculated. Regression equations were constructed using coefficient table obtained from this analysis.

\section{RESULTS}

Total of 250 heathy volunteers participated in the SMWT. Eight participants were excluded from the study as residual statistics presented them as potential outliers. Descriptive statistics and multiple regression analysis were run with 242 subjects. Mean age of the study population was $28.93 \pm 13.18$ years. We included patients of all age group ranging from 18 to 81 years. However, the maximum study population clustered around the age group of 18 to 49 years, amounting to $90.9 \%$ of the entire study population. Only $9.1 \%$ of the subjects were above 50 years. Male and female ratio was 2.16:1. We evaluated 166 males (68.6\%) and $76(31.4 \%)$ females volunteers. Male preponderance 
might have been due to army hospital set up. The mean HT and WT were $161.66 \pm 8.08 \mathrm{~cm}$ and $60.33 \pm 10.12 \mathrm{Kg}$, respectively. The average SMWD was $488.86 \pm 86.03$ ( 489 $\pm 86)$ meters. The mean distance walked by males was $508.88 \pm 82.11 \mathrm{~m}(\sim 509 \pm 82 \mathrm{~m})$ and females were 445.13 $\pm 78.27 \mathrm{~m}(\sim 445 \pm 78)$. The demographic and observed parameters are explained in table no. 1

Table 1. Demographic characteristics of the study population.

\begin{tabular}{|c|c|c|c|c|}
\hline $\begin{array}{l}\text { Age } \\
\text { Group } \\
\text { (yrs) }\end{array}$ & $\begin{array}{l}\text { SMWD } \pm S D \\
\text { (m) }\end{array}$ & $\begin{array}{l}\text { Height } \pm \text { SD } \\
(\mathrm{Cm})\end{array}$ & $\begin{array}{l}\text { Weight } \pm S D \\
\text { (Kgs) }\end{array}$ & $\begin{array}{l}\text { BMI } \pm S D \\
\left(\mathrm{Kg} / \mathrm{M}^{2}\right)\end{array}$ \\
\hline Under 20 & $476.28 \pm 54.33$ & $163.15 \pm 6.19$ & $60.40 \pm 9.91$ & $22.64 \pm 3.06$ \\
\hline 20 to 29 & $498.12 \pm 66.78$ & $163.05 \pm 7.01$ & $59.13 \pm 9.17$ & $22.17 \pm 2.61$ \\
\hline 30 to 39 & $548.60 \pm 100.37$ & $160.63 \pm 9.13$ & $65.11 \pm 10.84$ & $25.15 \pm 3.05$ \\
\hline 40 to 49 & $507.42 \pm 68.95$ & $157.78 \pm 7.12$ & $63.44 \pm 8.65$ & $25.74 \pm 5.24$ \\
\hline 50 to 59 & $459.19 \pm 80.02$ & $161.50 \pm 5.20$ & $61.25 \pm 14.37$ & $23.28 \pm 4.41$ \\
\hline 60 to 69 & $304.58 \pm 90.91$ & $158.33 \pm 14.38$ & $47.00 \pm 5.59$ & $19.46 \pm 5.79$ \\
\hline 70 to 79 & $319.53 \pm 90.62$ & $143.33 \pm 11.25$ & $53.00 \pm 9.67$ & $26.50 \pm 8.07$ \\
\hline $\begin{array}{l}80 \& \\
\text { above }\end{array}$ & $334.50 \pm 2.12$ & $162.50 \pm 0.00$ & $65.00 \pm 0.00$ & $24.62 \pm 0.00$ \\
\hline Total & $488.86 \pm 86.04$ & $161.66 \pm 8.09$ & $60.33 \pm 10.12$ & $23.10 \pm 3.66$ \\
\hline
\end{tabular}

The mean \pm SD of the pre-test and post-test changes in vital parameters are enlisted in table 2. All five independent variables were significantly correlated with SMWD. The highest correlation was for gender, WT and Age in descending order. We excluded BMI from this evaluation as it was significantly related with HT and WT.

Table 2. Pre-test and Post-test changes in Parameters in six minute walk test.

\begin{tabular}{|c|c|c|c|}
\hline & Mean \pm SD & & Mean \pm SD \\
\hline $\begin{array}{l}\text { Pre-test } \\
\text { Systolic BP }\end{array}$ & $112.56 \pm 11.05 \mathrm{mmHg}$ & $\begin{array}{l}\text { Post-test } \\
\text { Systolic BP }\end{array}$ & $120.31 \pm 15.04 \mathrm{mmHg}$ \\
\hline $\begin{array}{l}\text { Pre-test } \\
\text { Diastolic BP }\end{array}$ & $76.78 \pm 9.39 \mathrm{mmHg}$ & $\begin{array}{l}\text { Post-test } \\
\text { Diastolic BP }\end{array}$ & $79.06 \pm 8.52 \mathrm{mmHg}$ \\
\hline $\begin{array}{l}\text { Pre-test Borg } \\
\text { Score }\end{array}$ & $0.06 \pm 0.41$ & $\begin{array}{l}\text { Post-test } \\
\text { Borg Score }\end{array}$ & $0.67 \pm 1.51$ \\
\hline Pre-test HR & $94.89 \pm 16.49 / \mathrm{min}$ & Post-test HR & $110.38 \pm 22.22 / \mathrm{min}$ \\
\hline Pre-test $\mathrm{SpO}_{2}$ & $96.78 \pm 3.17 \%$ & $\begin{array}{l}\text { Post-test } \\
\mathrm{SpO}_{2}\end{array}$ & $96.17 \pm 4.57 \%$ \\
\hline
\end{tabular}

After running multiple linear regression analysis, $R, R^{2}$ and adjusted $R^{2}$ were calculated as $0.445,0.198$ and 0.183 , respectively. $R=0.445$ showed moderate level of correlation and prediction. $\mathrm{R}^{2}=0.198$ indicated that our independent variables explained $19.8 \%$ variability of our dependent variable. Good fit of the regression model to the data was identified $(p<0.05)$. $F$ value in ANOVA was 13.28. The constant was calculated as 421.994 ( 422$)$. The coefficients for all independent variables were as follows: age $=1.367(p=0.009)$, gender $=-48.917(p=0.001)$, height
Table 3. Proposed regression equations for prediction of six minute walk distance.

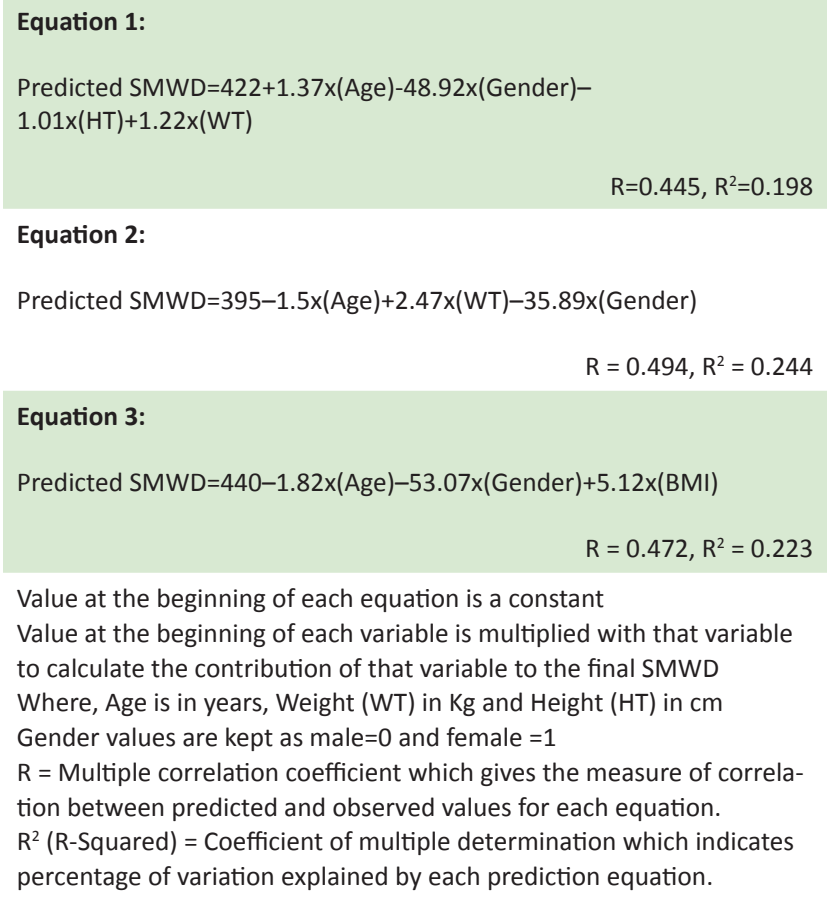

Value at the beginning of each equation is a constant

Value at the beginning of each variable is multiplied with that variable to calculate the contribution of that variable to the final SMWD Where, Age is in years, Weight (WT) in Kg and Height (HT) in cm Gender values are kept as male $=0$ and female $=1$

$\mathrm{R}=$ Multiple correlation coefficient which gives the measure of correlation between predicted and observed values for each equation. $R^{2}$ (R-Squared) = Coefficient of multiple determination which indicates percentage of variation explained by each prediction equation.

$=-1.0 .1(p=0.917)$ and weight=1.219 $(p=0.04)$. Hence the final regression equation was formulated as depicted in equation 1 of table no 3 .

We further evaluated the regression equation with age, Gender and WT, without HT as it did not show statistical significance on coefficient statistics. Hence the equation without HT was formulated as depicted in equation 2 of table 3. Our third regression analysis evaluated age, gender and BMI. The proposed equation 3 from this analysis is given in table 3. Predicted distances using all three equations were compared with the observed SMWD. It was seen that SMWD predicted with equation two and three predicted the distance more accurately than the first equation.

\section{DISCUSSION}

A 2001 review of functional walking tests concluded that SMWT is easy, better tolerated and good measure of daily activities. ${ }^{6}$ Most activities of daily living are performed at submaximal levels of exertion. ${ }^{5}$ Since then SMWT has been utilised in multitude of diseases for assessment of functional status and improvement. To be able to utilise this in Nepal, our study was an attempt at defining reference range and equations.

One of the initial investigations on reference equations of SMWD was done by Enright PL and Sherrill. This group of researchers where directly involved in 2002 ATS guidelines on SMWT. 117 healthy men and 173 healthy women, aged 40 to 80 years were evaluated. Pre and post-test $\mathrm{SpO}_{2}$, $H R$, and the degree of dyspnoea were determined. Like 
our study women walked shorter distance as compared to males. In this study SMWD was significantly less for men and women who were older, heavier, and shorter. The resulting gender-specific regression equations explained about $40 \%$ of the variance in the distance walked for healthy adults. ${ }^{8}$

Unlike the above study, our study had younger population and was more reliable for adults below 50 years of age. The best prediction of SMWD was observed for age groups between 18 to 40 years. It was due to this distribution that age had a relatively less contribution to the regression equation as compared to other independent variables. Studies for SMWD analysing small sample size and narrow age range had no significant correlation with age. ${ }^{17}$ However, age was a statistically significant variable for prediction with negative correlation $(p<0.001)$ in our study. Such negative correlation was also identified in other studies involving healthy adult population. ${ }^{8,18}$ The walking distance decreased with the increasing age in our study. This was attributed to age associated decrease in muscle mass and strength. ${ }^{19}$

This study showed a strong negative correlation with gender $(p<0.005)$. The male subjects walked greater distance as compared to females. Many studies have shown similar influence of gender on walking distance. ${ }^{8,20}$ Muscle mass, strength and height of male gender has been attributed for higher SMWD. ${ }^{20}$

The regression equation in this study had minimal influence from HT. The correlation was negative with $p=0.917$. Hence, it was removed on further evaluation. Similar dissociation of HT from SMWD was observed in the study conducted by Enright and Sherrill. ${ }^{8}$ In contrast to our findings, many studies have found HT as a significant predictor of SMWD. ${ }^{17,18}$ Studies involving growing children with wide range of $\mathrm{HT}$ had greater significance of $\mathrm{HT}$ in regression equation. ${ }^{21,22}$ The HT of our study population below 50 years of age ranged between 157 to $163 \mathrm{~cm}$. This narrow range might have been the reason for non-significant association.

Our study showed positive influence of WT on SMWD. WT tends to have minimal influence on walk-studies done on adults. ${ }^{8,18}$ Study conducted by Lammers et al. on children showed linear correlation between WT and SMWD up to 30 kgs. ${ }^{21}$ In a review article, Victor Z. Dourado explains that the inconsistent correlation between WT and SMWD might have been due to the curvilinear relation. A linear regression model may not detect this correlation. ${ }^{23}$

Our study provided three possible equations for the prediction of SMWD in healthy adult population below 50 years of age. We tested all three equations for the predictability of the actual distance walked by each study subjects. Second equation with age, WT, gender and third equation with age, gender, BMI most accurately predicted the SMWD in our study population. A single regression equation is given for prediction of SMWD for both the gender. Similar single equations for both gender have been formulated in several standard studies. ${ }^{18,24-26}$ Our study evaluated the recommended standard demographic parameters for the prediction equation. Unlike this study Li et al utilised absolute difference in HR as an independent variable. $^{22}$ Similarly, regression equation from Poh et al. used 'percentage of maximum HR at the end of the test' as a predictor of SMWD. Though we recorded pre and post-test $\mathrm{HR}$, It was not included prospectively as an independent variable for prediction. Hence, it was not taken into consideration during analysis.

Our third equation predicted SMWD using BMI, as our study showed significant correlation with BMI $(p<0.001)$. Many studies have in fact found BMI to be statistically not significant. ${ }^{8,17,18,27,28}$ Gibbon et al and Li et al showed a weak correlation of BMI to SMWD with $r=-0.27$ and 0.11 respectively. ${ }^{22,24}$ These findings are in contrast with our findings of BMI with good prediction capability.

Our work is limited in few aspects. We included motivated and willing volunteers. By doing so we might have introduced selection bias. Clustering of our population below the age group of 50 years have made the equation less reliable for subjects above 50 years. In this study we have not allowed pre-test warming up and re-test after the first test. Hence, we cannot comment on the changes in the distance with practice and re-test. Recent ERS/ATS technical standards in field walk test states the existence of strong learning effect in SMWT. ${ }^{29}$

\section{CONCLUSION}

This study evaluated a Nepalese cohort and provided regression equations and reference range for the normal healthy adults in Nepal. The average SMWD was $488.86 \pm$ $86.03 \mathrm{~m}$. This study also showed that gender, age, weight and BMI are good predictors of SMWD. We propose the use of second and third regression equations of this study for the prediction of SMWD in adults in Nepal, as these were derived from local population as per 2014 ERS/ATS recommendation. ${ }^{29}$ However, prediction is less accurate for the age group above 50 years. The predicted normal distance can be utilised in the comparison of sub-maximal exercise capacity in the diseased subjects.

\section{ACKNOWLEDGMENT}

The authors wish to acknowledge all the volunteers who actively participated in the study including all the staffs of Shree Birendra Hospital, Chhauni and National Academy of Medical Sciences, Bir Hospital, Maha Boudha. 


\section{REFERENCES}

1. Cooper $\mathrm{KH}$. A means of assessing maximal oxygen intake: correlation between field and treadmill testing. JAMA. 1968 Jan 15;203(3):201-4.

2. Enright PL. The six-minute walk test. Respir Care. 2003 Aug;48(8): 783-5.

3. Wasserman K, Hansen JE, Sue DY, Casaburi R, Whipp BJ. Principles of exercise testing and interpretation; including pathophysiology and clinical application. 3rd ed. Philadelphia: Lippincott, Williams \& Wilkins; 1999. p. xv.

4. Weisman IM, Zeballos RJ. An integrated approach to the interpretation of cardiopulmonary exercise testing. Clin Chest Med. 1994 Jun;15(2):421-45.

5. American Thoracic Society. American Thoracic Society statement: guidelines for the six-minute walk test. Am J Respir Crit Care Med. 2002;166:111-7.

6. Solway S, Brooks D, Lacasse $\mathrm{Y}$, Thomas S. A qualitative systematic overview of the measurement properties of functional walk tests used in the cardiorespiratory domain. Chest. 2001 Jan;119(1):256-70.

7. Cahalin L, Pappagianopoulos P, Prevost S, Wain J, Ginns L. The relationship of the 6-min walk test to maximal oxygen consumption in transplant candidates with end-stage lung disease. Chest. 1995 Aug;108(2):452-9.

8. Enright PL, Sherrill DL. Reference equations for the six-minute walk in healthy adults. Am J Respir Crit Care Med. 1998 Nov;158:1384-7.

9. Chetta A, Zanini A, Pisi G, Aiello M, Tzani P, Neri M, et al. Reference values for the 6-min walk test in healthy subjects 20-50 years old. Respir Med. 2006;Sep;100(9):1573-8.

10. Casanova C, Celli BR, Barria P, Casas A, Cote C, de Torres JP et al. The 6-min walk distance in healthy subjects: reference standards from seven countries. Eur Respir J. 2011 Jan;37(1):150-6.

11. Guyatt GH, Thompson PJ, Berman LB, Sullivan MJ, Townsend M, Jones NL et al. How should we measure function in patients with chronic heart and lung disease?. J Chronic Dis. 1985;38:517-24.

12. Guyatt GH, Townsend M, Keller J, Singer J, Nogradi S. Measuring functional status in chronic lung disease: conclusions from a random control trial. Respir Med. 1991 Sep;85(Suppl B):17-21.

13. Niederman MS, Clemente PH, Fein AM, Feinsilver SH, Robinson DA, Ilowite JS et al. Benefits of a multidisciplinary pulmonary rehabilitation program: improvements are independent of lung function. Chest. $1991 \mathrm{Apr} ; 99(4): 798-804$

14. Butland RJA, Pang J, Gross ER, Woodcock AA, Geddes DM. Two, six-, and 12-minute walking tests in respiratory disease. BMJ. 1982;284:1607-8.
15. Knox AJ, Morrison JF, Muers MF. Reproducibility of walking test results in chronic obstructive airways disease. Thorax. 1988 May;43(5): 388-92.

16. Noseda A, Carpiaux JP, Prigogine T, Schmerber J. Lung function, maximum and submaximum exercise testing in COPD patients: reproducibility over a long interval. Lung. 1989;167(4):247-57.

17. Camarri B, Eastwood PR, Cecinsa NM, Thompson PJ, Jenkins S. Six minute walk distance in healthy subjects aged $55-75$ years. Respir Med. 2006;100, 658-65.

18. Troosters T, Gosselink R, Decramer M. Six minute walking distance in healthy elderly subjects. Eur Respir J. 1999 Aug;14(2):270-4.

19. Evans WJ, Campbell WW. Sarcopenia and age-related changes in body composition and functional capacity. J Nutr. 1993; 123 (2 Suppl): 465-8.

20. Dourado VZ, Vidotto MC, Guerra RLF. Reference equations for the performance of healthy adults on field walking tests. J Bras Pneumol. 2011 Sep-Oct; 37(5): 607-14.

21. Lammers AE, Hislop AA, Flynn Y, Haworth SG. The 6-minute walk test: normal values for children of 4-11 years of age. Arch Dis Child. 2008; 93 (6): 464-8.

22. Li AM, Yin J, Au JT, So HK, Tsang T, Wong E, et al. Standard reference for the six-minute-walk test in healthy children aged 7 to 16 years. Am J Respir Crit Care Med. 2007; 176 (2): 174-80.

23. Dourado VZ. Reference equations for the 6-minute walk test in healthy individuals. Arq Bras Cardiol. 2011 Feb 25;96:e128-38.

24. Gibbons WJ, Fruchter N, Sloan S, Levy RD. Reference values for a multiple repetition 6-minute walk test in healthy adults older than 20 years. J Cardiopulm Rehabil. 2001;21(2):87-93.

25. Ben Saad H, Prefaut C, Tabka Z, Mtir AH, Chemit M, Hassaoune R, et al. 6-minute walk distance in healthy North Africans older than 40 years: influence of parity. Respir Med. 2009;103(1):74-84.

26. Masmoudi K, Aouicha MS, Fki H, Dammak J, Zouari N. The six minute walk test: which predictive values to apply for Tunisian subjects aged between 40 and 80 years?. Tunis Med. 2008;86(1):20-6.

27. Poh H, Eastwood PR, Cecins NM, Ho KT, Jenkins SC. Six-minute walk distance in healthy Singaporean adults cannot be predicted using reference equations derived from Caucasian populations. Respirology. 2006;11(2):211-6.

28. Priesnitz CV, Rodrigues GH, Stumpf Cda S, Viapiana G, Cabral CP, Stein $\mathrm{RT}$, et al. Reference values for the 6-min walk test in healthy children aged 6-12 years. Pediatr Pulmonol. 2009;44(12):1174-9.

29. Holland AE, Spruit MA, Troosters T, Puhan MA, Pepin V, Saey D et al. An official European Respiratory Society/ American Thoracic Society Technical Standard: field walking tests in chronic respiratory disease. Eur Respir J 2014 [In press DOI: 10.1183/09031936.00150314]. 